\title{
Non-Woven Textiles Formed from Contact Drawn Poly(Ethylene Oxide) Fibers Provide Tunable Filtration and Virucidal Properties via Entrapment of Silver Nanoparticles
}

Samuel J. Baldwin ${ }^{1}$, Patrick D. Slaine ${ }^{2}$,Erin Keltie ${ }^{3}$, Swomitra Palit ${ }^{1}$, Sarah L. McKinnell ${ }^{4}$, Brittany E. Longpré ${ }^{4}$, Kristin Robin Ko ${ }^{1}$, Jennifer Green ${ }^{4}$, Gary Markle ${ }^{4}$, Jong Sung Kim ${ }^{2,3}$, Craig McCormick ${ }^{3}$, and John P. Frampton ${ }^{1, *}$

${ }^{1}$ School of Biomedical Engineering, Dalhousie University, 5981 University Avenue, Halifax, NS B3H 4R2 CANADA; ${ }^{2}$ Department of Microbiology \& Immunology, Dalhousie University, 5850 College Street, Halifax, NS B3H 4R2 CANADA; ${ }^{3}$ Department of Community Health \& Epidemiology, Dalhousie University, Life Sciences Research Institute, 1348 Summer Street, Halifax, NS B3H 4R2 CANADA; ${ }^{4}$ Textile Department, NSCAD University, NSCAD University 5163 Duke Street, Halifax NS B3J 3J6 CANADA; *To whom correspondence should be addressed: framptonjp@gmail.com 


\section{SUPPLEMENTAL METHODOLOGY}

\section{Filtration Testing System}

The aerosol generator consisted of an atomizer (TSI model 3076), diffusion drier (TSI model 3062), aerosol neutralizer (TSI model 3088), and a mixing chamber. Compressed air was passed through a high-efficiency particulate air filter to supply the atomizer, which generated a constant size distribution of particles (count median diameter $\sim 75 \mathrm{~nm}$ ) from the sample fluid. The sample fluid was a $1.5 \% \mathrm{w} / \mathrm{w}$ solution of sodium chloride in $18.2 \mathrm{M} \Omega \mathrm{cm}$ water. The aerosol generated by the atomizer then passed through a diffusion drier, which lowered the RH of the aerosol to $20 \%$ before passing though the neutralizer, which stripped the particles of bound charges. Finally, the uncharged aerosol was diluted with additional dry, filtered compressed air before entering the mixing chamber at a flow rate of 7-8 $\mathrm{L} \mathrm{min}^{-1}$. The volume of the mixing chamber was $60 \mathrm{~L}$.

The sample assembly was attached to the outlet of the mixing chamber and consisted of an inline stainless steel $25 \mathrm{~mm}$ diameter filter holder (Pall Laboratory). The high- and low-pressure ports of a differential manometer (MKS model 223BD-00010AAU) were installed directly before and after the sample assembly to measure the pressure drop across the filter. The manometer was configured to output a voltage between 0 and $1 \mathrm{~V}$, and its full-scale range was 0 1333.2 Pa. The voltage output from the manometer was measured with a multimeter to convert to $\mathrm{Pa}$.

Two SMPSs were used to simultaneously measure the particle number concentration and size distribution in the aerosol from the mixing chamber and the particle number concentration and size distribution that passed through filter samples. SMPS1, which characterized the aerosol from the mixing chamber, consisted of an Electrostatic Classifier (TSI model 3080) and Condensation Particle Counter (CPC; TSI model 3775). The total sample flow rate of SMPS1 was $0.3 \mathrm{~L} \mathrm{~min}^{-1}$. SMPS2, which measured the particle number concentration and size distribution that passed through the filter samples, consisted of an Electrostatic Classifier (TSI model 3082) and CPC (TSI model 3772). The total sample flow rate of SMPS2 was $1 \mathrm{~L} \mathrm{~min}^{-1}$.

NIOSH guidelines for testing N95 masks specify that masks must be challenged with an aerosol flow rate of $85 \mathrm{~L} \mathrm{~min}^{-1}$ (Office of the Federal Register, 2020). A full N95 mask has a surface area of approximately $150 \mathrm{~cm}^{2}$, so the face velocity of the NIOSH procedure was approximately $0.57 \mathrm{~L}\left(\mathrm{~min} \mathrm{~cm}^{2}\right)^{-1}$. The surface area of filter samples held by the $25 \mathrm{~mm}$ diameter sample assembly was $4.91 \mathrm{~cm}^{2}$. The aerosol flow rate was adjusted to $2.8 \mathrm{~L} \mathrm{~min}^{-1}$ to have a consistent face velocity of aerosol challenging the filter samples as detailed by NIOSH guidelines. A constant aerosol flow rate across the filter sample was maintained by an excess flow line comprised of a HEPA filter, mass flow controller (Alicat Scientific model MCRW-20SLPM$\mathrm{D} / 5 \mathrm{M}$ ), and pump (KNF model UN86KT.45P), installed down-line from the sample assembly and SMPSs. The combined flow rates of SMPS2 $\left(1 \mathrm{~L} \mathrm{~min}^{-1}\right)$ and the excess flow line $\left(2 \mathrm{~L} \mathrm{~min}^{-1}\right)$ resulted in a total aerosol flow rate of $3 \mathrm{~L} \mathrm{~min}^{-1}$ across the filter sample. 


\section{SUPPLEMENTAL FIGURES \& LEGENDS}

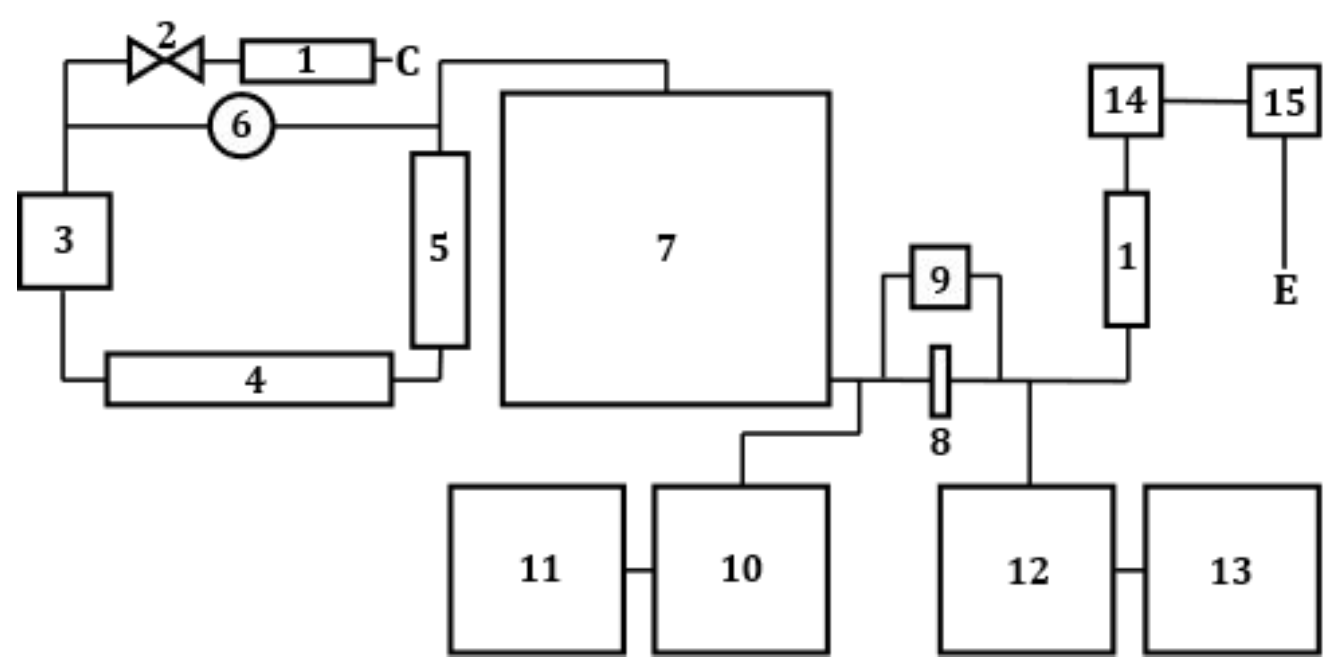

Figure S1: The filter testing system was comprised of an aerosol generator, sample assembly (8), differential manometer, two Scanning Mobility Particle Sizers (SMPSs), and an excess flow line. Schematic Key: $\mathrm{C}=$ compressed air source; $\mathrm{E}=$ exhaust. $1=$ HEPA filter; $2=$ gas regulator; 3 atomizer; $4=$ diffusion drier; $5=$ neutralizer; $6=$ rotameter with flow meter; $7=$ mixing chamber; $8=$ sample assembly; $9=$ differential manometer; $10=$ Electrostatic Classifier $1 ; 11=$ CPC 1;12 = Electrostatic Classifier 2;13 = CPC 2; $14=$ flow controller; $15=$ pump. 


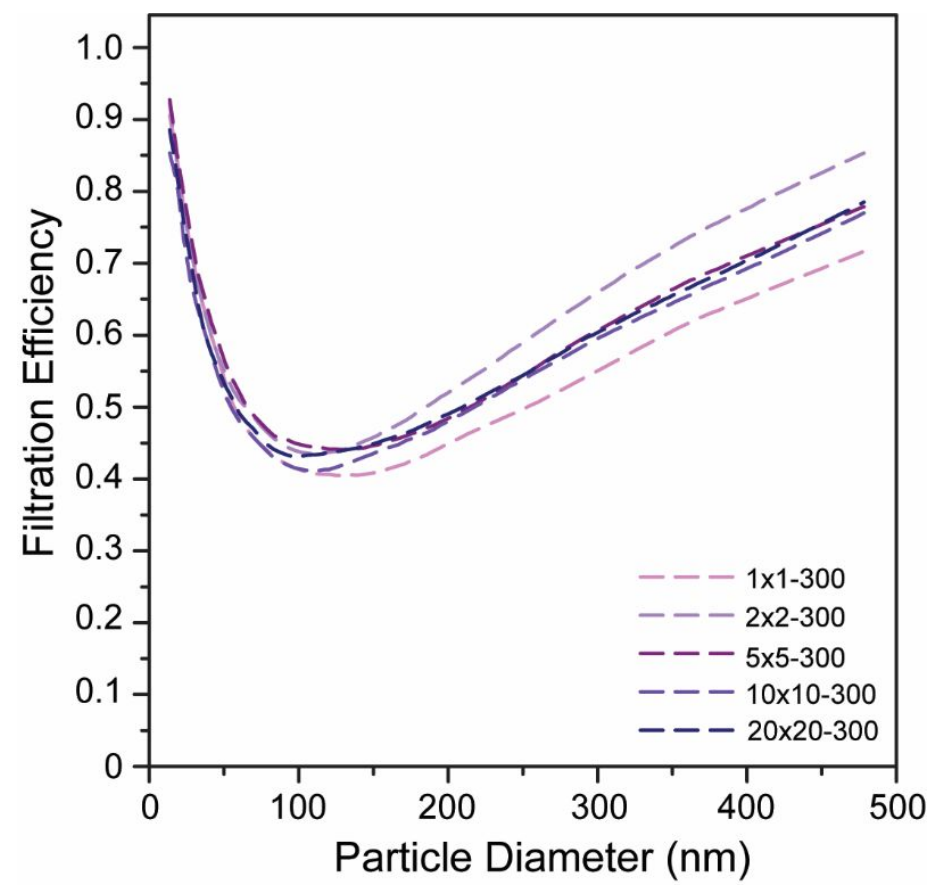

Figure S2: Filtration efficiency as a function of particle diameter for the 300 elongation cycle series of PEO filtration media. 


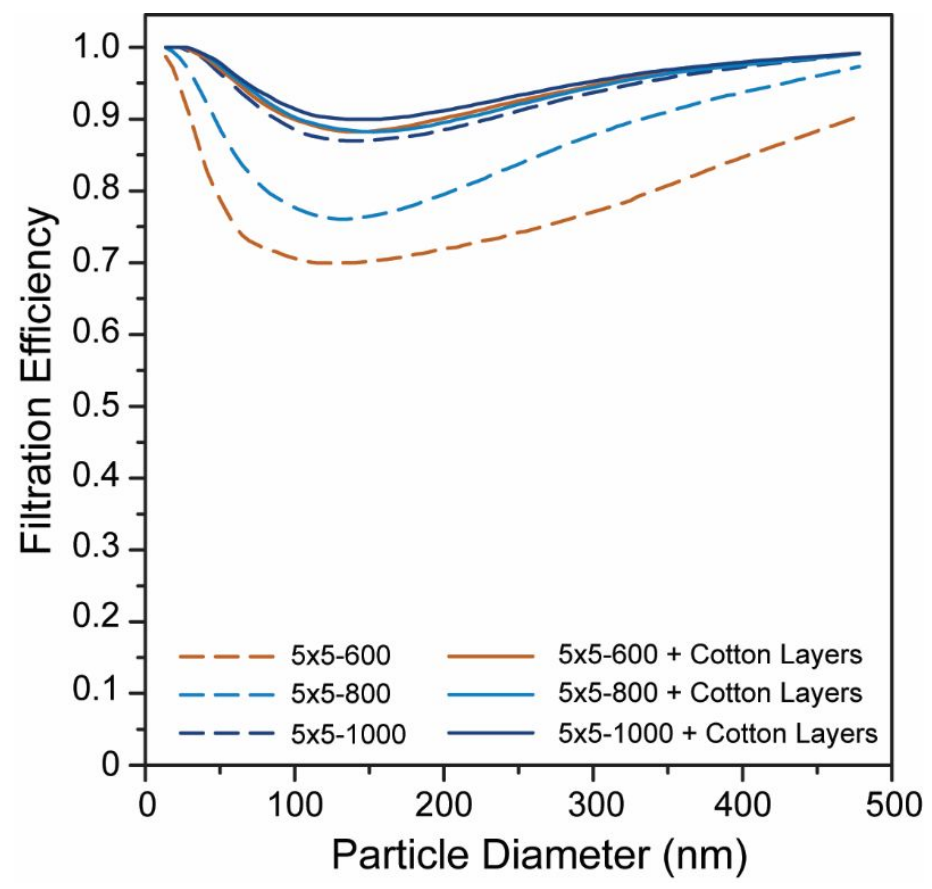

Figure S3: Filtration efficiency as a function of particle diameter for $5 \times 5-600,-800$, and -1000 PEO filtration media with and without cotton cloth layers. 


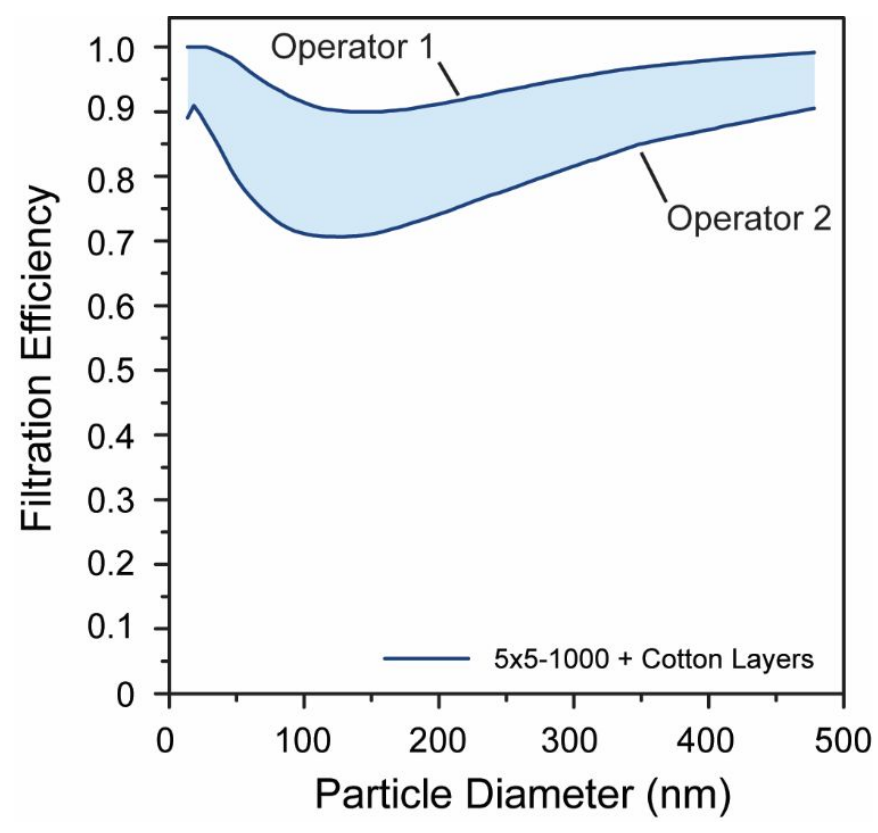

Figure S4: Variation in filtration performance as a function of operator conducting the contact drawing process. Filtration efficiency varied between $78 \%$ and $94 \%$ for the $5 \times 5-1000$ filtration media. 

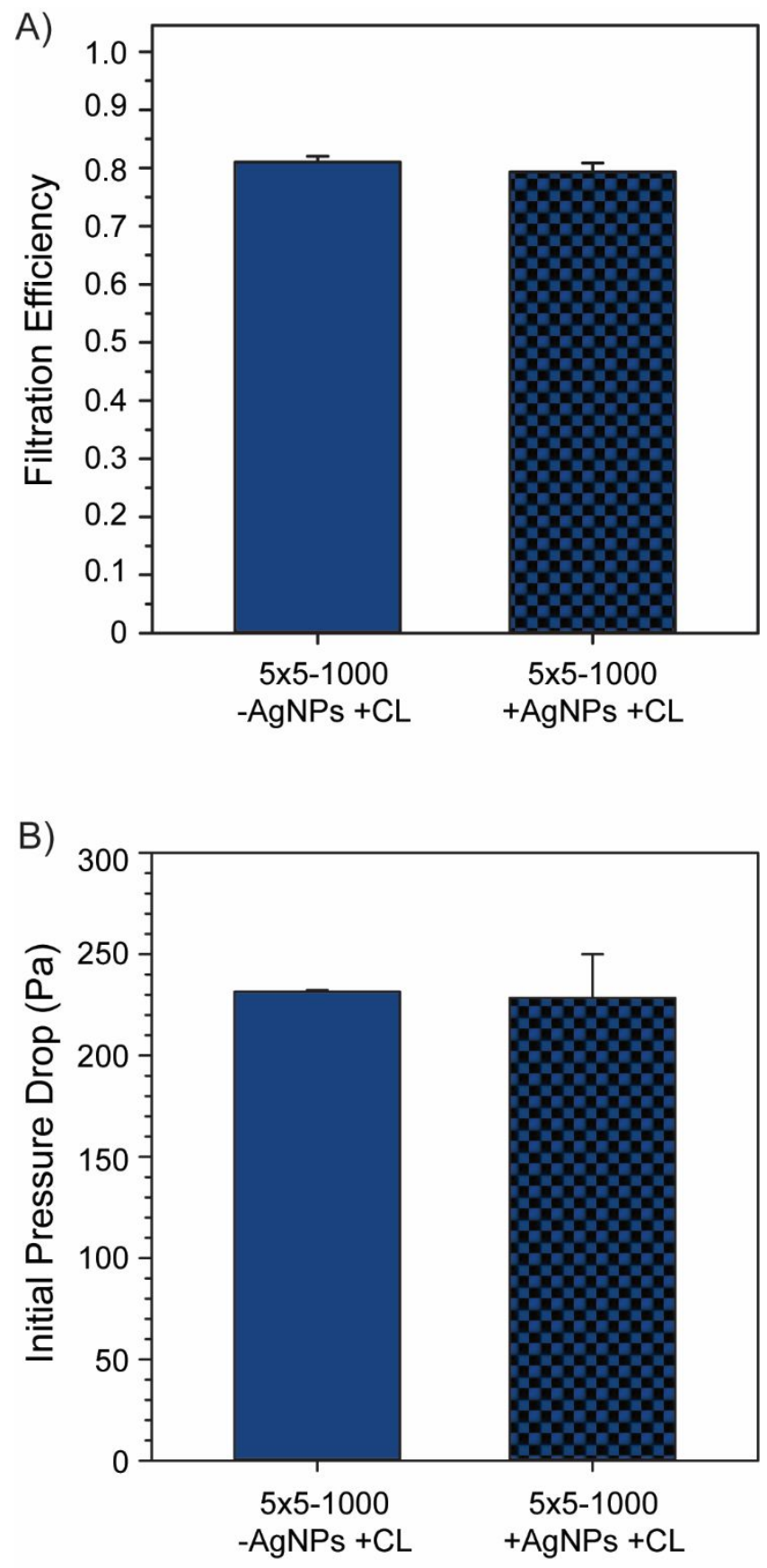

Figure S5: No significance differences in (A) filtration efficiency and (B) initial pressure drop (were observed between the 5x5-1000 + cotton layers (CL) media formed using PEO fibers and PEO fibers containing entrapped AgNPs. All fabrication replicates were performed by the same operator to eliminate inter-operator variability in hand manufacturing. 